\title{
Slip Line Theory Based Stability Analysis on the Influence of Deep Excavation on Adjacent Slope
}

\author{
Aizhao Zhou, ${ }^{1}$ Chengchao Li $\left(\mathbb{D},{ }^{1}\right.$ Pengming Jiang, ${ }^{1}$ Kai Yao $\mathbb{D}^{2},{ }^{2}$ Na Li, ${ }^{3}$ and Wei Wang ${ }^{3}$ \\ ${ }^{1}$ Department of Civil and Architecture Engineering, Jiangsu University of Science and Technology, Zhenjiang, Jiangsu 212003, China \\ ${ }^{2}$ Department of Civil \& Environmental Engineering, National University of Singapore, Singapore 117576 \\ ${ }^{3}$ School of Civil Engineering, Shaoxing University, Shaoxing, Zhejiang 312000, China
}

Correspondence should be addressed to Kai Yao; yaokai@u.nus.edu and Wei Wang; wellswang@usx.edu.cn

Received 1 February 2018; Accepted 16 May 2018; Published 24 June 2018

Academic Editor: Edoardo Artioli

Copyright (C) 2018 Aizhao Zhou et al. This is an open access article distributed under the Creative Commons Attribution License, which permits unrestricted use, distribution, and reproduction in any medium, provided the original work is properly cited.

\begin{abstract}
The impact of deep excavation to the stability of adjacent slope is evaluated based on the slip line theory. Stress field of slope under various excavation conditions is simulated by finite element method, while slip line field is determined by non-associated flow rule. Factor of safety is obtained by integrating the skid-resistance and the shear stress on each slip line, and the slip line with minimum factor of safety corresponds to the critical slip surface. Two typical displacement constraint boundaries are considered. The results indicate that the critical slip surface moves towards to the slope surface and develops downwards. The factor of safety decreases with the excavation process. For flexible displacement constraint boundary, large deformation of supporting pile causes obvious variation of critical slip surface and factor of safety. In terms of the stiff displacement constraint boundary with internal supports, deep excavation only has limited effect on the slope stability.
\end{abstract}

\section{Introduction}

The buildings are extensively crowded with the rapid development of city, leading to complex construction sites for deep excavation. The situation is more serious in hilly areas like Chongqing in China, as there are numerous slopes adjacent to the excavation sites. Deep excavation adjacent to a slope brings about a lot of challenges for the engineers, as the sliding mechanism of slope tends to be more complicated. The excavation disrupts the original earth pressure balance in the field. Moreover, the supporting structures for deep excavation impose restrictions for the displacement of slope toe and the soils behind the structures. Thus, the commonly used limit equilibrium method (LEM) is no more available $[1,2]$. Luo [3] investigated the slope stability whereby deep excavation is around the slope toe by strength reduction method (SRM), considering the effect of excavation depth and soil parameters. The stress and displacement fields can be obtained through SRM under the failure state of slope, in order to achieve the factor of safety based on the constitutive model $[4,5]$. However, SRM could not analyze the influence of supporting structure stiffness on the slope stability. Therefore, the variation of factor of safety and critical slip surface is unavailable under different working conditions.

According to the theory of plastic mechanics, slip line method is to take the soils as a rigid-plastic material and generate a slip line field for the ultimate volume force which satisfies the boundary conditions [6-8]. Zhu et al. [9] proposed a more practical "potential slip line theory" by treating soil as elastoplasticity material. This method is able to calculate the factor of safety and identify the critical slip surface of slope based on the stress field generated by finite element method (FEM). In this paper, the stress fields of slope under various excavation conditions are simulated by FEM, considering the stiffness of supporting structure. Based on the above analysis, the distribution of slip lines in the slope are then obtained according to stress characteristic equation. Finally the corresponding factor of safety on each slip line is figured out by integrating the stress in the slip line field. The slip line with the minimum factor of safety is the critical slip surface of slope for various excavation conditions. Two typical displacement constraint boundaries are considered, 


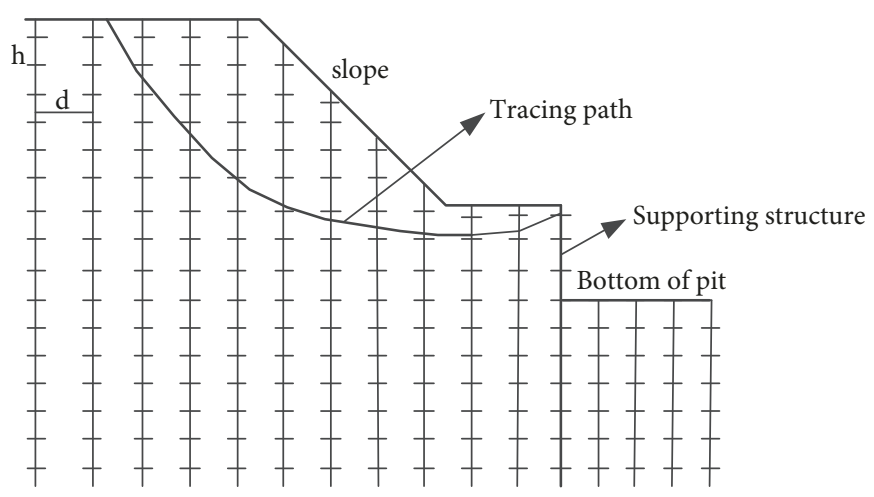

Figure 1: Tracing paths and control points ( $h$ and $d$ refer to the element dimension).

namely, flexible displacement constraint boundary and stiff displacement constraint boundary.

\section{Stress Field during Excavation}

To simulate the stress filed during excavation by FEM, the calculation process can be divided into several steps:

(1) The initial stress field $\left\{\sigma_{0}\right\}$ and displacement field $\left\{\delta_{0}\right\}$ in the site caused by deadweight and external load are calculated before deep excavation. Taking into account the fact that the soil is completely consolidated before excavation, the initial displacement field $\left\{\delta_{0}\right\}=0$.

(2) Calculate the subsidiary stress field $\left\{\Delta \sigma_{i}\right\}$ and displacement field $\left\{\Delta \delta_{i}\right\}$ caused by the first unloading due to excavation and the construction of supporting structures. Then the total stress field $\left\{\sigma_{i}\right\}$ and displacement field $\left\{\delta_{i}\right\}$ in the site are as follows:

$$
\begin{aligned}
& \left\{\sigma_{i}\right\}=\left\{\sigma_{i-1}\right\}+\left\{\Delta \sigma_{i}\right\} \\
& \left\{\delta_{i}\right\}=\left\{\delta_{i-1}\right\}+\left\{\Delta \delta_{i}\right\}
\end{aligned}
$$

(3) The second step is repeated until the final stress field $\{\sigma\}$ and displacement field $\{\delta\}$ are obtained:

$$
\begin{aligned}
& \{\sigma\}=\left\{\sigma_{0}\right\}+\sum\left\{\Delta \sigma_{i}\right\} \\
& \{\delta\}=\left\{\delta_{0}\right\}+\sum\left\{\Delta \delta_{i}\right\}
\end{aligned}
$$

In order to generate the slip line field and ensure the uniformity of slip line variation in the tracing path, the control points and grids are applied, as shown in Figure 1.

\section{Slip Line Field}

For the plane strain condition, two mutually perpendicular principal stresses are there at any point on the plane [10]. By connecting the lines representing the principal stress direction at each point, two clusters of curves orthogonal to each other can be obtained. They are called principal stress traces, which can be shown as lines 1-1 and 2-2 in Figure 2.

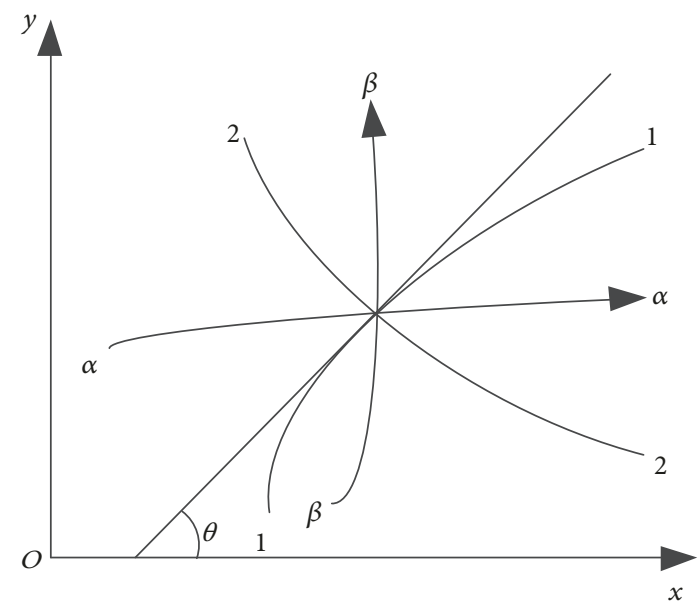

FIgURE 2: Principal stress traces and slip lines.

For soils in plastic state, there are two shear failure surfaces at each point [10]. By connecting the shear failure surface (or slip surface) of each point, two clusters of curves named slip line are generated shown as lines $\alpha-\alpha$ and $\beta-\beta$ in Figure 2 . The tangential direction of one point on the slip line is the direction of the sliding surface of the corresponding point. $\theta$ is the angle between the tangent direction of major principal stress and $\mathrm{x}$ axis.

For Mohr-Coulomb model based on the associated flow rule, the angle $\mu$ between the slip line and the principal stress is calculated by the following [11]:

$$
\mu=\frac{\pi}{2}-\frac{\varphi}{2}
$$

in which, $\varphi$ is the internal friction angle.

However, it is reported that soil does not follow the associated flow rule (e.g., $[12,13])$. Moreover, the associated flow rule overestimates the dilatancy of soils, resulting in nonconservative calculation of slope stability [13-15]. Up to now, Davis [16], Drescher and Detournay [14], and Yang and Huang [17] generated the slip line field by non-associated flow rule with adjusted soil strength parameters. It was indicated 
that the relationship between normal stress and shear stress on the slip line is similar to Mohr-Coulomb criterion:

$$
F=\tau^{\prime}-c^{\prime}-\sigma_{n}^{\prime} \tan \varphi^{\prime}
$$

where the strength parameters $c^{\prime}$ and $\varphi^{\prime}$ have similar mechanical function with parameters $c$ and $\varphi$ of Mohr-Coulomb criterion. Their relationships can be represented as follows:

$$
\frac{c^{\prime}}{c}=\frac{\tan \varphi^{\prime}}{\tan \varphi}=\frac{\cos \psi \cos \varphi}{1-\sin \psi \sin \varphi}
$$

where $\psi$ is the dilatancy angle of soil.

The main difference between non-associated flow rule and associated flow rule lies on the selection of dilatancy angle. When the dilatancy angle $\psi$ is taken to be equal to the angle of shearing resistance $\varphi$, it is associated flow rule. When $0 \leq \psi<\varphi$, the soil obeys non-associated flow rule. Kong et al. [18] investigated the dilatancy angle for geomaterials under the non-associated flow rule and found that $\psi$ can be selected as $\varphi / 2$ instead of just treating $\psi$ to be zero. Therefore, in this paper, $\psi$ is set as $\varphi / 2$.

In terms of non-associated flow rule, the angle between slip line and the major principal stress $\left(\mu^{\prime}\right)$ in the plastic region should be adjusted to the following:

$$
\mu^{\prime}=\frac{\pi}{4}-\frac{\psi}{2}
$$

while the characteristic equations for slip line $\alpha$ and line $\beta$ are described as

$$
\begin{aligned}
& \frac{d y}{d x}=\tan \left(\theta-\mu^{\prime}\right) \quad(\text { slip line } \alpha) \\
& \frac{d y}{d x}=\tan \left(\theta+\mu^{\prime}\right) \quad(\text { slip line } \beta)
\end{aligned}
$$

According to the "potential slip line theory" proposed by Zhu et al. [9], there are two sliding surfaces orthogonal to each other with the smallest vertical shear capacity for each point in the elastic region. Corresponding to angle $\mu^{\prime}$ in plastic region, the angle in elastic region $\mu_{e}$ is adjusted to be

$$
\mu_{e}=\frac{\pi}{4}-\frac{\theta_{\max }}{2}
$$

where $\theta_{\max }=\arcsin \left(\left(\left(\sigma_{1}-\sigma_{3}\right) / 2\right) /\left(-\left(\sigma_{1}-\sigma_{3}\right) / 2+c \cot \varphi\right)\right)$. $\sigma_{1}$ and $\sigma_{3}$ are the maximum principal stress and minimum principal stress, respectively.

As shown in Figure 1, mesh size is controlled by the point spaces $h$ and $d$. Small space will lead to high accuracy of the determination of slip line field. The stress of unit node is obtained by FEM, while the direction of slip line at each point is calculated by the above method. The first point can be anyone except those on the top of the slope. The direction of slip line at next nearby point follows that of the current point. In general, the intersection of the slip line and the control path does not fall on the control points. It is necessary to determine the sliding direction of the intersection by linear interpolation of the adjacent upper and lower control points. Then the above steps are repeated until a complete slip line is formed to the boundary supporting structure. Various slip lines will be generated for different starting points, by which the slip line field is determined.

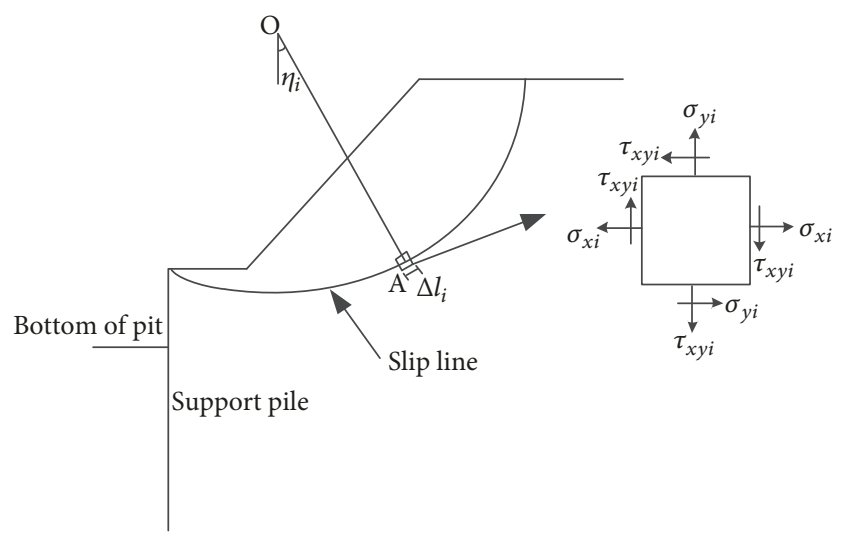

FIGURE 3: Stresses on the slip line.

\section{Factor of Safety}

Conventionally, factor of safety is defined as the ratio of the slip resistance to the downward force, while, for each slip line, it is the ratio of the total shear strength to the shear stress on the arc segment. During the path tracing of slip line, the stresses $\sigma_{x i}, \sigma_{y i}$, and $\tau_{x y i}$ at each point on slip line and the maximum principal stress angle $\theta$ can be calculated by FEM. In Figure 3, the slip line can be treated as a combination of many continuous small segments $\Delta l_{i}$. The equivalent stress on each segment can be represented by the average stress of the two nearby points. For example of the equivalent center point A on the segment $\Delta l_{i}$, its stresses are as follows:

$$
\begin{aligned}
\bar{\sigma}_{x i} & =\frac{\sigma_{x i}+\sigma_{x(i+1)}}{2} \\
\bar{\sigma}_{y i} & =\frac{\sigma_{y i}+\sigma_{y(i+1)}}{2} \\
\bar{\tau}_{x y i} & =\frac{\sigma_{x y i}+\sigma_{x y(i+1)}}{2}
\end{aligned}
$$

while its angle between the tangent direction of major principal stress and $\mathrm{x}$ axis is

$$
\bar{\theta}_{i}=\frac{\left(\theta_{i}+\theta_{i+1}\right)}{2}
$$

Assuming that the angle between the segment $\Delta l_{i}$ and horizon is $\eta_{i}$, the equivalent normal stress $\bar{\sigma}_{n i}$ and shear stress $\bar{\tau}_{i}$ are

$$
\begin{aligned}
\bar{\sigma}_{n i}= & \frac{1}{2}\left(\bar{\sigma}_{x i}+\bar{\sigma}_{y i}\right)-\frac{1}{2}\left(\bar{\sigma}_{x i}-\bar{\sigma}_{y i}\right) \cos 2 \eta_{i} \\
& +\bar{\tau}_{x y i} \sin 2 \eta_{i} \\
\bar{\tau}_{i}= & -\frac{1}{2}\left(\bar{\sigma}_{x i}-\bar{\sigma}_{y i}\right) \sin 2 \eta_{i}+\bar{\tau}_{x y i} \cos 2 \eta_{i}
\end{aligned}
$$

where $\eta_{i}=\theta_{i}-\mu$ and $\mu=\pi / 4-\varphi / 4$, according to the nonassociated flow rule.

After getting the equivalent normal stress and shear stress of all the segments on the slip line, the total shear force and 
TABLE 1: Deep excavation process.

\begin{tabular}{lc}
\hline Process & Finite element analysis \\
\hline Step 1 & Initial stress calculation (dead-weight plus a uniform load of 20kPa ) \\
Step 2 & Construction of bored piles and first support \\
Step 3 & Excavation to 3m depth and construction of second support \\
Step 4 & Excavation to the bottom of the pit \\
Step 5 & Construction of baseboard \\
\hline
\end{tabular}

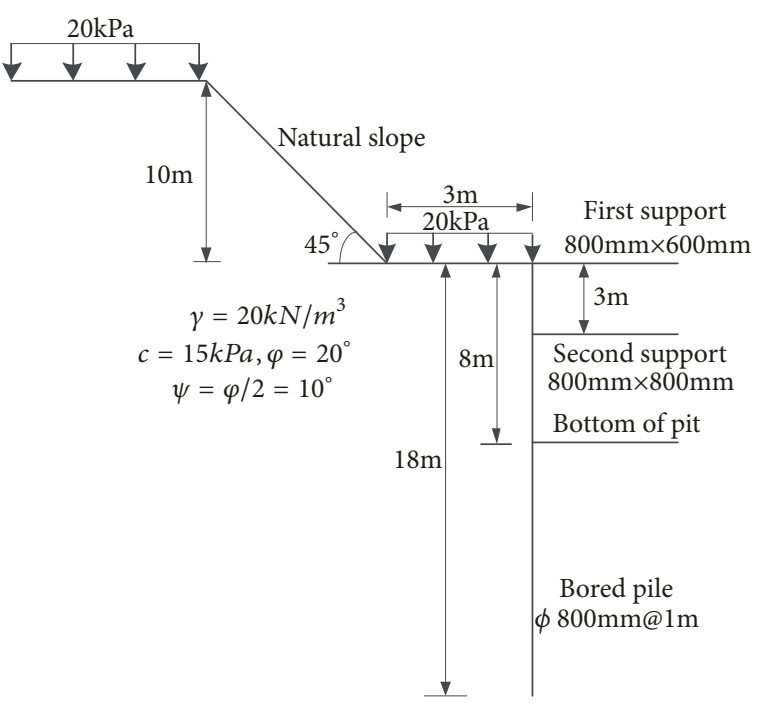

FIGURE 4: Modelling and soil parameters.

shear strength along the entire slip line are achieved. Thus, the factor of safety corresponding to each slip line is

$$
F_{s}=\frac{\sum_{i=1}^{n}\left(c+\bar{\sigma}_{n i} \tan \varphi\right) \Delta l_{i}}{\sum_{i=1}^{n} \bar{\tau}_{i} \Delta l_{i}}
$$

where $n$ represents the number of elements on the slip line. Since the factor of safety can be obtained by integration of shear stress and shear strength on each slip line, the critical slip surface is the slip line with the minimum factor of safety.

\section{Case Study}

5.1. Modelling and Soil Parameters. Figure 4 shows the modelling and soil parameters for the slope adjacent to deep excavation. The soil is simplified as a single homogeneous layer. The supporting structures are $3 \mathrm{~m}$ adjacent to the slope toe, while the excavation depth is $8 \mathrm{~m}$. The process for deep excavation is summarized in Table 1 .

5.2. Flexible Displacement Constraint Boundary. According to Shen [19], the problems of earth pressure can be divided into three categories according to different boundary conditions. Bearing capacity of foundation and earth pressure of retaining wall belong to the first category, while earth pressure of tunnel belongs to the third category. Slope stability and deep excavation support are classified under the second category, which is to calculate the ultimate load resulting in

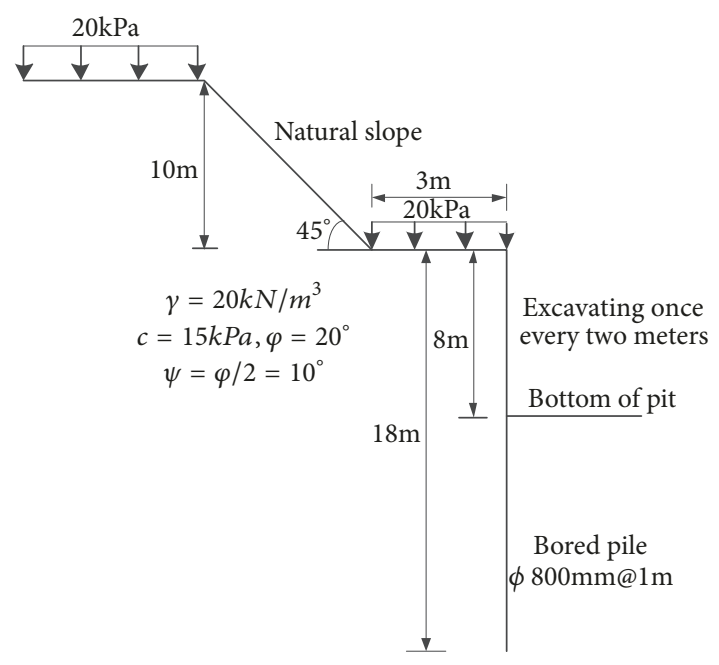

FIGURE 5: Calculation model with weak displacement constraint boundary.

the rigid body sliding with knowledge of the external load. The boundary is unconstraint for natural slope. Oppositely, the boundary of deep excavation support is displacement constraint. For deep excavation adjacent to a steep slope like the case shown in Figure 4, the bored pile is to take the earth pressure. Due to the unbalanced earth pressure around the retaining pile, there may be some amount of deformation on the pile resulting in further sliding of the slope to the excavation side. Thus, the boundary is flexible displacement constraint. Figure 5 shows the calculation model, considering the bored piles as support structure. Excavation is conducted once every two meters, by then the position of critical slip surface and factor of safety under different excavation conditions are also calculated. Specific analysis of excavation process is shown in Table 2.

Figure 6 illustrates that variation of critical slip surface with the process of excavation. It can be identified that the critical slip surface gradually moves to the slope surface and develops downward. In Figure 7, it can be seen that the factor of safety almost reduces linearly with the step of excavation. The supporting bored pile restrains the displacement of slope toe, preventing the slope from sliding towards the foundation pit. Therefore from step 1 to step 2, the end of slip surface moves towards the slope toe, resulting in smaller factor of safety (increased downward force with reduced slip resistance). Due to the excavation process from step 3, the deformation of bored pile gradually increases leading to 
TABLE 2: Excavation process under weak displacement constraint boundary.

\begin{tabular}{lc}
\hline Process & Finite element analysis \\
\hline Step 1 & Initial stress calculation (dead-weight plus a uniform load of 20kPa ) \\
Step 2 & Construction of bored piles \\
Step $3 \sim 6$ & Excavating once every two meters \\
\hline
\end{tabular}

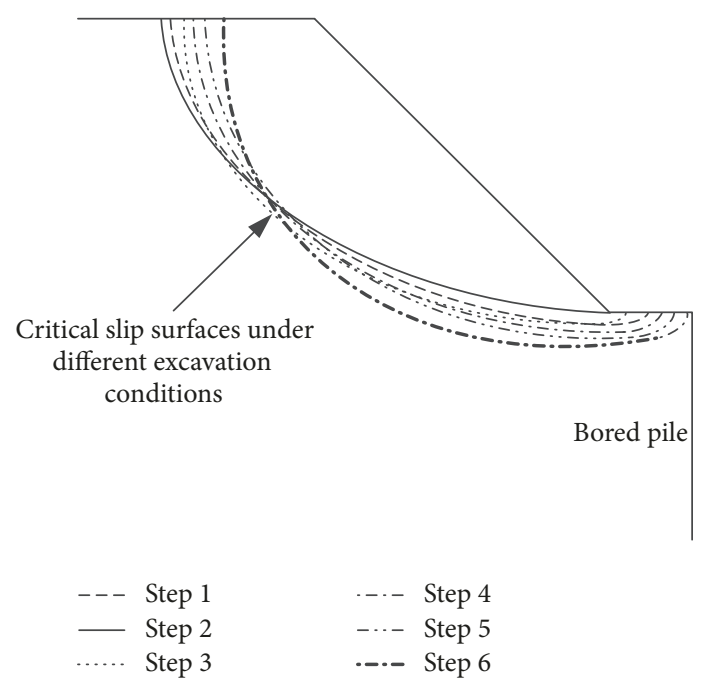

Figure 6: Distribution of critical slip surfaces under different excavation process.

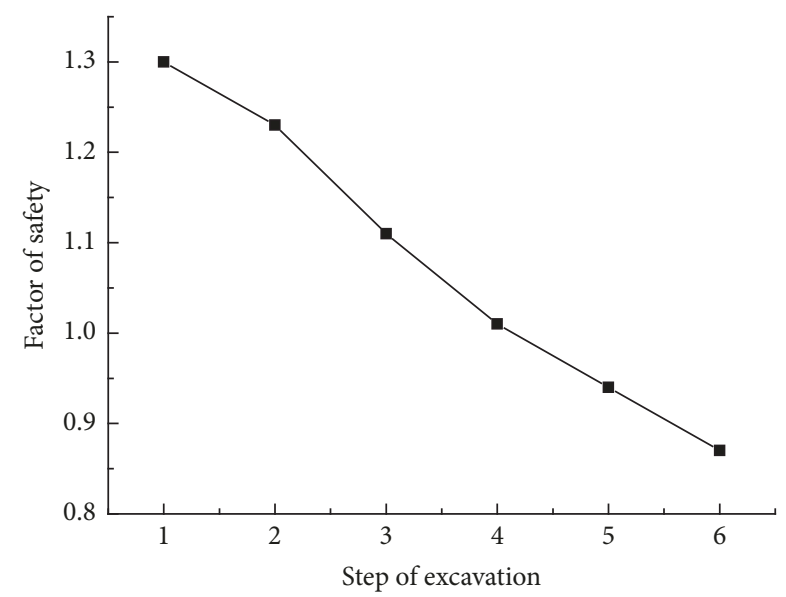

FIgURE 7: Variation of factor of safety under different excavation process.

gradually weakened displacement constraint boundary. Then the soil behind the supporting pile slides towards the pit, and the shape of slip surface develops from the original arc to an approximately logarithmic helix. For the whole excavation process, the calculated factor of safety gradually reduces from the initial 1.30 (step 1) to 0.87 (step 6). So it reveals that deep excavation has a significant impact on the stability of adjacent slope. The construction of supporting structure leads to the variation of critical slip surface. If only replying on bored piles

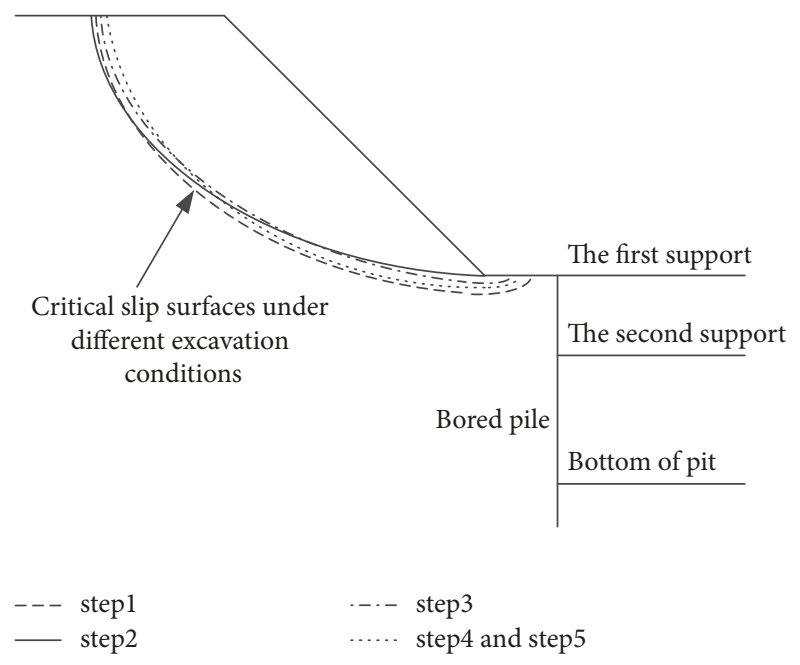

Figure 8: Distribution of critical slip surfaces under different excavation process.

as supporting structure, its deformation is large. However, the pile does not fail as the sliding force is less than the shear strength of pile. Bending of the pile will push the soil to slide to the pile head, so the displacement of pile head is large. Thus, restriction of the pile head movement is an effective way for improving the slope stability.

5.3. Stiff Displacement Constraint Boundary. With the internal support for the bored pile (like first and second support in Figure 8), the deformation of supporting pile is rigidly limited. So the support structure with both bored pile and internal supports is considered as a stiff displacement constraint boundary. For this case, the calculation model and excavation process can refer to Figure 4 and Table 1, respectively.

It can be identified from Figure 8 that the excavation has a limited effect on the critical slip surface because of the stiff displacement constraint boundary. The trend of slip surfaces is similar to that of the flexible displacement constraint boundary, as the critical slip surface also gradually moves to the slope surface and develops downward. However, the variation of slip surfaces is smaller. Compared with the critical slip surface of slope under natural state, the size of sliding block is slightly reduced due to the excavation. As shown in Figure 9, factor of safety reduces from 1.30 to 1.02 during the excavation. However, the construction of baseboard (step 5 in Table 1) does not make any difference to slope stability. The above findings are due to that the 


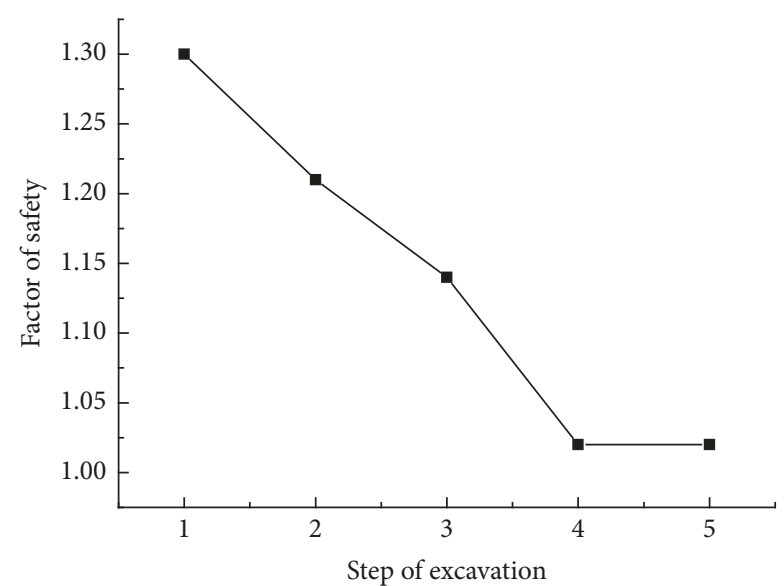

FIGURE 9: Variation of factor of safety under different excavation process.

two internal supports have greatly limited the deformation of the pile, weakening the influence of excavation on the slope stability. But some impact still exists due to the deep excavation.

\section{Conclusion}

Based on the "potential slip line theory" proposed by Zhu et al. [9], corresponding slip line field is built by considering the stress fields under different excavation conditions with FEM. Factor of safety is obtained with numerical integration of shear stress and shear strength on each slip line, and the critical slip surface is the one with the least factor of safety. Compared with traditional computing methods of slope stability, the method adopted in this study can effectively simulate the variation of slip surface and factor of safety under different excavation conditions. Two typical boundary conditions (i.e., flexible displacement constraint boundary and stiff displacement constraint boundary) are taken into account for the slope stability. For each boundary condition, the variation of critical slip surfaces and factor of safety are investigated. For the case with flexible displacement constraint boundary, due to excavation, the critical slip surface gradually moves to slope surface and develops downward, while the factor of safety gradually reduces. As the function of internal support of stiff displacement constraint boundary, excavation has smaller effect on slope stability compared with the case of flexible displacement constraint boundary, although the variations of critical slip surface and factor of safety show similar trend. It implies that the stiff supporting structure is beneficial for the safety of adjacent slope during deep excavation.

It should be noted that the limitation of this study is that uniform soil profile is adopted for the analysis. However, the soil condition is always complex and randomly distributed in the construction site. Since spatial variations of soil properties have been reported recently (e.g., [20]), further research considering nonhomogeneous soils will be conducted in the future.

\section{Data Availability}

All the data used to support the findings of this study are included within the article.

\section{Conflicts of Interest}

The authors declare that they have no conflicts of interest.

\section{Acknowledgments}

This study was financially cosupported by the National Natural Science Foundation of China (Grants nos. 51579119 and NO.41772311) and the Natural Science Foundation of Zhejiang Province (no. LY17E080016).

\section{References}

[1] A. W. Bishop, "The use of the slip circle in the stability analysis of slopes," Géotechnique, vol. 5, no. 1, pp. 7-17, 1955.

[2] D. G. Fredlund and J. Krahn, "Comparison of slope stability methods of analysis," Canadian Geotechnical Journal, vol. 14, no. 3, pp. 429-439, 1977.

[3] L. Peng, The soil stability analysis of soft soil slope toe excavation. Master Thesis [Master, thesis], Hefei University of Technology, Hefei, China, 2013 (Chinese).

[4] T. Matsui and K. C. San, "Finite element slope stability analysis by shear strength reduction technique," Soils and Foundations, vol. 32, no. 1, pp. 59-70, 1992.

[5] H. Zheng, G. H. Sun, and D. F. Liu, "A practical procedure for searching critical slip surfaces of slopes based on the strength reduction technique," Computers \& Geosciences, vol. 36, no. 1-2, pp. 1-5, 2009.

[6] W. Chen, "Preface," in Limit Analysis and Soil Plasticity, vol. 7 of Developments in Geotechnical Engineering, pp. IX-X, Elsevier, 1975.

[7] D. C. Drucker and W. Prager, "Soil mechanics and plastic analysis or limit design," Quarterly of Applied Mathematics, vol. 10, pp. 157-165, 1952.

[8] W. F. Chen and X. L. Liu, Limit analysis in soil mechanics, Elsevier, 2012.

[9] Y.-W. Zhu, C.-Q. Wu, and Y.-Q. Cai, "Determination of slip surface in slope based on theory of slip line field," Yanshilixue Yu Gongcheng Xuebao/Chinese Journal of Rock Mechanics and Engineering, vol. 24, no. 15, pp. 2609-2616, 2005.

[10] Y. R. Zheng, C. J. Deng, and J. L. Wang, "The study of slip line field and upper bound method based on the non-associated flow rule," Engineering Science, vol. 8, no. 12, pp. 56-69, 2010 (Chinese).

[11] O. C. Zienkiewicz, C. Humpheson, and R. W. Lewis, "Associated and non-associated visco-plasticity and plasticity in soil mechanics," Géotechnique, vol. 25, no. 4, pp. 671-689, 1975.

[12] P. A. Vermeer and R. de Borst, "Non-associated plasticity for soils, concrete and rock," Heron, vol. 29, no. 3, 1984.

[13] Y.-J. Wang, J.-H. Yin, and C. F. Lee, “The influence of a nonassociated flow rule on the calculation of the factor of safety of soil slopes," International Journal for Numerical and Analytical Methods in Geomechanics, vol. 25, no. 13, pp. 1351-1359, 2001.

[14] A. Drescher and E. Detournay, "Limit load in translational failure mechanisms for associative and non-associative materials," Géotechnique, vol. 43, no. 3, pp. 443-456, 1993. 
[15] S. Melentijevic, A. Serrano, C. Olalla, and R. A. Galindo, "Incorporation of non-associative flow rules into rock slope stability analysis," International Journal of Rock Mechanics and Mining Sciences, vol. 96, pp. 47-57, 2017.

[16] E. H. Davis, "Theories of plasticity and the failure of soil masses," in Soil Mechanics Selected Topics, K. Lee, Ed., 1968.

[17] X.-L. Yang and F. Huang, "Slope stability analysis considering joined influences of nonlinearity and dilation," Journal of Central South University of Technology (English Edition), vol. 16, no. 2, pp. 292-296, 2009.

[18] W.-X. Kong, Y.-Q. Rui, and B.-D. Dong, "Determination of dilatancy angle for geomaterials under non-associated flow rule," Yantu Lixue/Rock and Soil Mechanics, vol. 30, no. 11, pp. 3278-3282, 2009.

[19] Z. J. Shen, Discontinuous solution in limit earth pressure computation application, Tsinghua University Press, Beijing, China, 2005.

[20] Y. Liu, W. Zhang, L. Zhang, Z. Zhu, J. Hu, and H. Wei, "Probabilistic stability analyses of undrained slopes by 3D random fields and finite element methods," Geoscience Frontiers, 2017. 


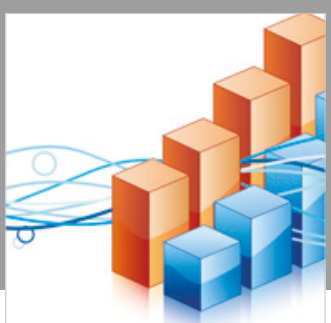

Advances in

Operations Research

\section{-n-m}
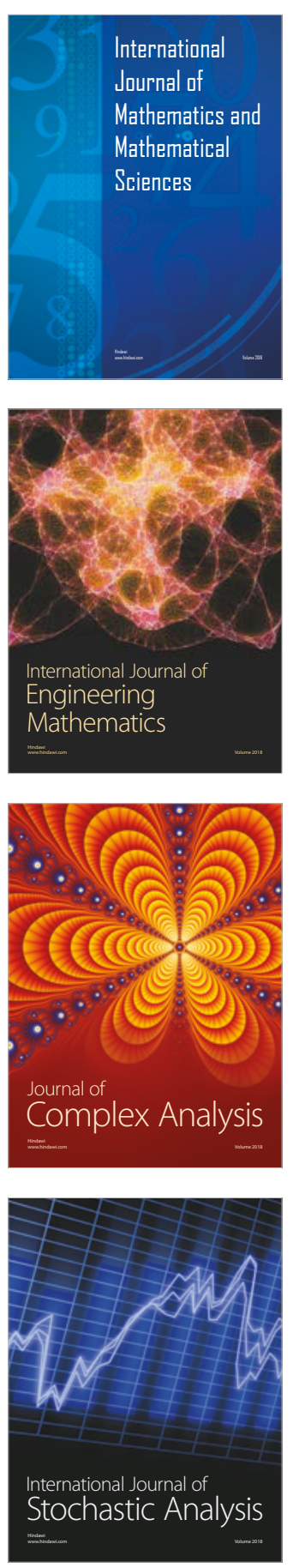
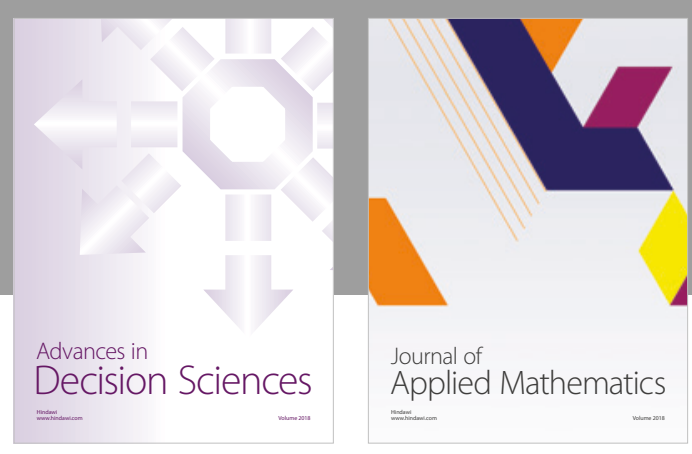

Journal of

Applied Mathematics
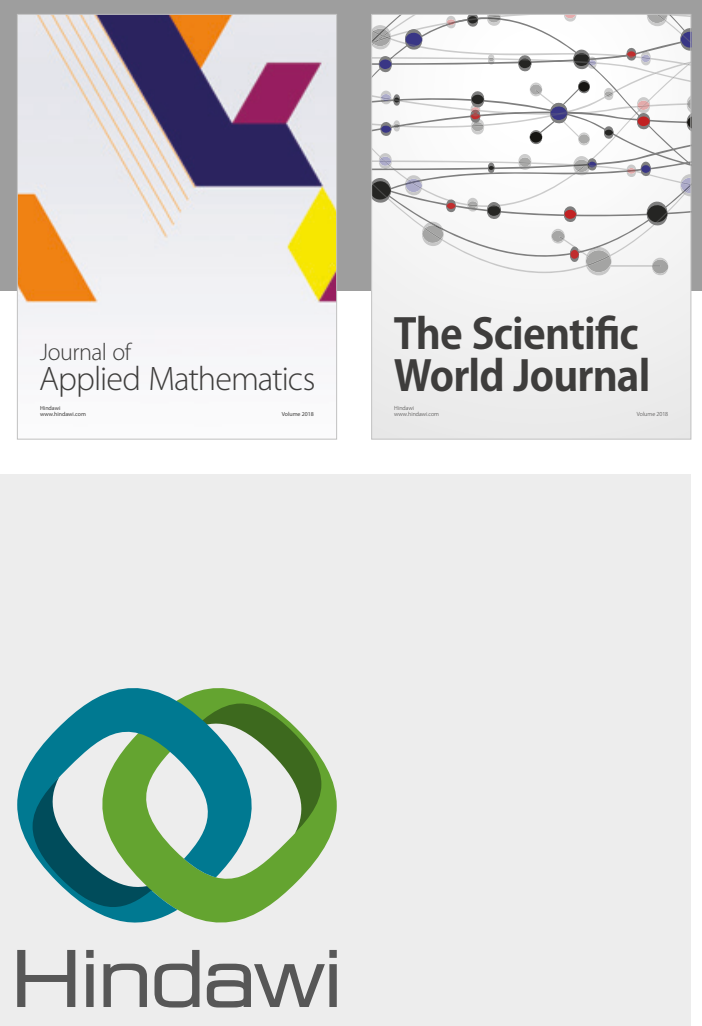

Submit your manuscripts at

www.hindawi.com

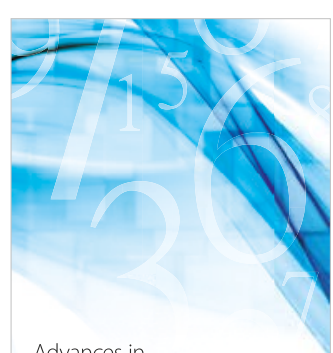

Advances in
Numerical Analysis
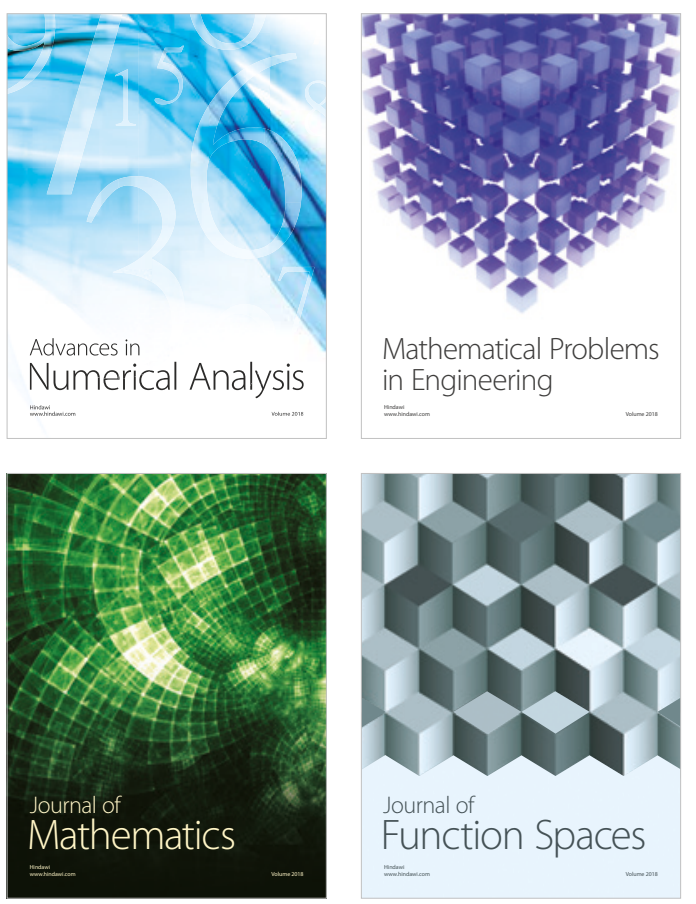

Mathematical Problems in Engineering

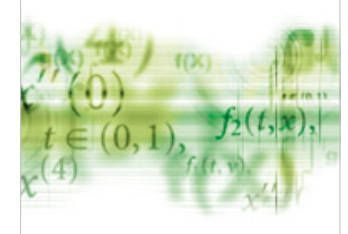

International Journal of

Differential Equations

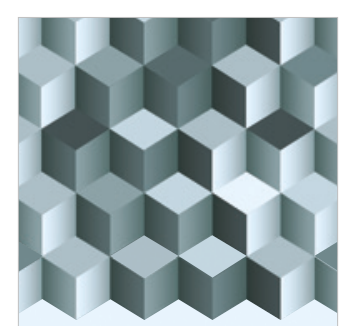

Journal of

Function Spaces

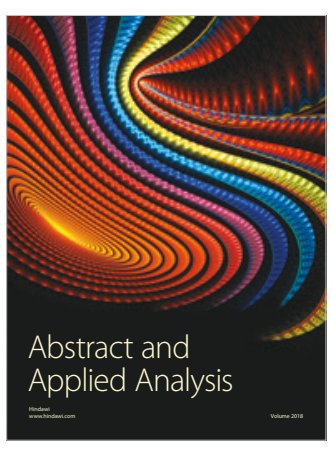

The Scientific

World Journal

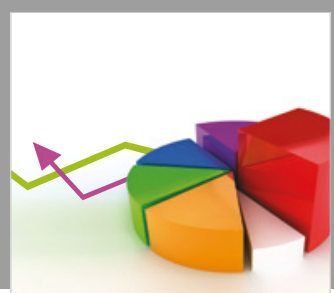

Journal of

Probability and Statistics
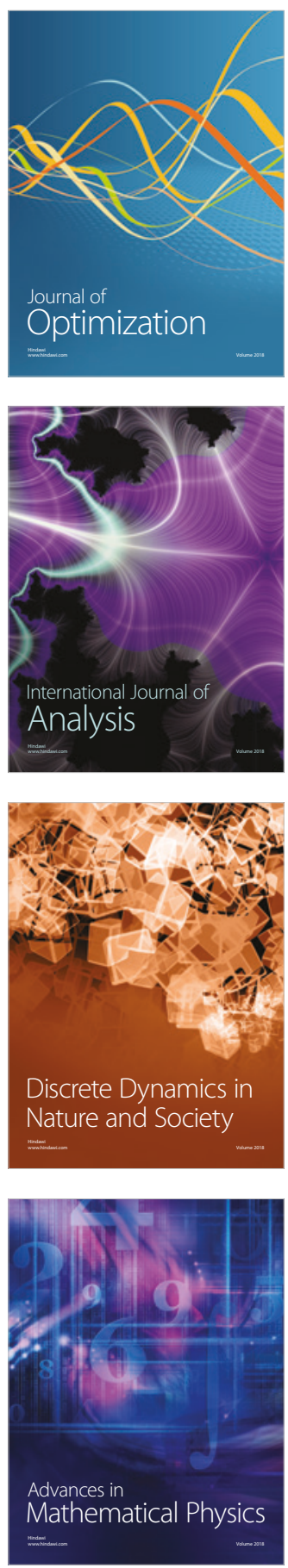